\title{
GameMaking: Uma Metodologia para o Ensino de In- formática para Alunos do Ensino Fundamental através da criação de Jogos Digitais
}

\author{
GameMaking: A Methodology to Teach Informatics for Middle School Students \\ through the Creation of Digital Games
}

\author{
Thiago Silva Mello \\ Universidade Federal da Paraíba - Campus IV \\ Rua da Mangueira, SN -Rio Tinto - PB \\ thiago.mello@dce.ufpb.br
}

\author{
Ayla Dantas \\ Universidade Federal da Paraíba - Campus IV \\ Rua da Mangueira, SN -Rio Tinto - PB \\ ayla@dce.ufpb.br
}

\begin{abstract}
Resumo Considerando jogos eletrônicos como um grande atrativo de entretenimento de pessoas de todas as idades, incluindo os jovens, este trabalho busca propor e avaliar uma metodologia de ensino de informática para turmas do ensino fundamental II baseada na produção de jogos eletrônicos por intermédio da ferramenta de autoria GameMaker. A metodologia foi projetada para tentar introduzir em aulas de informática para o ensino fundamental atividades relacionadas ao desenvolvimento de jogos simples, utilizando princípios pedagógicos propostos pela literatura. $\mathrm{Na}$ avaliação da metodologia proposta foram executadas as atividades previstas pela metodologia junto aos alunos de uma escola. Além disso, foram analisados os resultados produzidos pelos alunos nas aulas de informática e suas respostas a um questionário online e anônimo de avaliação.
\end{abstract}

Palavras-Chave: Jogos eletrônicos, ensino de informática, GameMaker

\begin{abstract}
Considering that games are an attractive entertainment for people of all ages, including teanagers, this work proposes a methodology to teach informatics to middle school students based on the development of games using the GameMaker authoring tool. The methodology was planned trying to introduce activities related to the development of simple games and following pedagogical principles proposed by the literature. During the methodology evaluation, the activities proposed there were executed with the students of a school. Moreover, the results produced by students in informatics classes and their responses to an online anonymous questionnaire were analyzed.
\end{abstract}

Keywords: Electronic Games, Informatics Teaching, GameMaker 


\section{Introdução}

As Tecnologias da Informação e Comunicação (TICs) vêm sendo utilizadas cada vez mais nas escolas. Lucena e Fuks [10] afirmam que a inserção de novas tecnologias na educação faz com que o aluno tenha mais interesse e motivação para estudar, modificando o paradigma da educação tradicional para um ensino mais atrativo.

O crescente avanço da indústria de entretenimento tem atraído cada vez mais os jovens para o computador. Um dos grandes atrativos oferecidos são os jogos eletrônicos. Para Mattar [13], um jogo pode ser considerado um meio em que as pessoas interagem através de conceitos e onde jogadores assumem papeis realistas para resolverem determinados problemas. Alguns jogos podem ter fins educacionais. Sendo assim, um jogo pode ser aplicado em sala de aula de maneira contextualizada, proporcionando a aprendizagem de forma lúdica, com a ajuda do professor e proporcionando uma interação com o aluno [20]. Algumas vezes, o próprio desenvolvimento de jogos pode ser um aspecto explorado para atrair alunos para a área de informática de forma geral e para desenvolver sua capacidade intelectual. O uso de tecnologia para o desenvolvimento de um jogo reflete no desenvolvimento intelectual do indivíduo, pois o aluno adquire habilidades de raciocínio que the possibilitarão aprender algo sozinho [22].

Há relatos positivos na literatura sobre o uso de atividades na escola referentes ao desenvolvimento de jogos. Um desses relatos é apresentado por Carmichael [3], ao afirmar que o desenvolvimento de jogos por alunos do ensino médio serviu na escolha da tecnologia da informação como profissão de alguns. Esta mesma ideia é ressaltada pelo trabalho de Seabom, El-Nasr, Milan et al. [19], onde se afirma que o desenvolvimento de jogos eletrônicos proporcionou uma boa aceitação dos estudantes pela área da computação.

Há um déficit de profissionais da área de computação e é importante ressaltar que o número de mulheres na computação vem caindo a cada ano. É necessário explorar meios que proporcionem o interesse das mulheres pela informática. Neste caso, o autor sugere um currículo programático nas escolas para que crianças e jovens conheçam mais a área da tecnologia da informação por meio dos jogos [5].

Partindo desses pontos de vista, realizou-se uma pesquisa sistemática na literatura para investigar trabalhos relacionados ao uso de programação através de jogos no ensino fundamental. A partir dessa investigação, observou-se que existem poucos trabalhos relacionados com desenvolvimento de jogos com alunos do ensino fundamental e que há trabalhos focados em alunos do ensino médio.

Considerando este aspecto e que seria relevante investigar experiências dessa natureza com alunos mais novos, este trabalho apresenta uma metodologia para o ensino de informática para alunos do ensino fundamental. Acreditase que para esta fase é necessária uma pedagogia diferenciada dos demais níveis de ensino, pois atribuir aulas dinâmicas e materiais instrucionais voltados à realidade destes alunos é uma tarefa bastante relevante para estimular esse público a adquirir fluência em tecnologia da informação.

A partir desse cenário, percebe-se que criar uma metodologia com aulas de informática para alunos do ensino fundamental que busque ensinar desenvolvimento de jogos aumenta a motivação dos alunos para participar de aulas de informática. Além disso, observou-se que é possível ter como resultados de tais aulas, jogos desenvolvidos pelos alunos. Portanto, buscou-se delinear uma metodologia pedagógica para introduzir a estudantes do ensino fundamental conceitos de criação de jogos eletrônicos através do auxilio de ferramentas de autoria. Segundo Leffa [9], ferramentas de autoria são programas usados para melhorar a elaboração de conteúdos digitais através de recursos multimídias já existentes (imagens, textos, sons e vídeos).

Neste trabalho é apresentada uma metodologia para o ensino de conceitos relacionados ao desenvolvimento de jogos para alunos do ensino fundamental e um estudo de caso com alunos do $6^{\circ}$ ao $9^{\circ}$ ano do ensino fundamental de uma escola particular da cidade de João Pessoa. Nesse estudo de caso foram introduzidos aos alunos conceitos de criação de jogos (Sprite, Objects, Background, Room) através da ferramenta GameMaker 8.1 e os alunos foram motivados a desenvolver jogos durante as aulas. Posteriormente eles avaliaram sua experiência e os dados desta avaliação foram analisados.

As demais seções deste artigo estão organizadas conforme se descreve a seguir. A Seção 2 apresenta a metodologia utilizada na pesquisa. A Seção 3 apresenta alguns trabalhos relacionados. A Seção 4 dá alguns detalhes sobre a ferramenta de autoria GameMaker. A Seção 5 apresenta a metodologia de ensino proposta por este trabalho, denominada GameMaking. A Seção 6 descreve o estudo de caso realizado e seus resultados. Por fim, a Seção 7 apresenta as conclusões deste trabalho e propostas de trabalhos futuros.

\section{Metodologia da Pesquisa}

Nesta seção são detalhadas as fases desta pesquisa e os métodos utilizados durante sua execução. 


\subsection{Pesquisa Bibliográfica}

Diante da necessidade de investigar informações sobre desenvolvimento de jogos com alunos do ensino fundamental, o primeiro passo deste trabalho foi realizar uma pesquisa bibliográfica em busca de trabalhos publicados pela comunidade científica sobre este assunto.

Através deste modo de pesquisa e utilizando como bases de dados principais as bibliotecas digitais da ACM e IEEE, não foi possível observar trabalhos relacionados com desenvolvimento de jogos com alunos do ensino fundamental similares ao que se propõe no presente artigo. Isso motivou a realização de um estudo de caso de caráter exploratório para identificar a viabilidade e nível de aceitação dos alunos quanto à aplicação da metodologia de ensino proposta por esse trabalho, que foi denominada GameMaking.

\subsection{Pesquisa Exploratória}

Para descobrir se é viável introduzir conceitos de desenvolvimento de jogos com estudantes do ensino fundamental por meio de uma metodologia de ensino, ou seja, tentar ampliar o grau de conhecimento sobre este tema, foi realizada uma pesquisa exploratória.

A pesquisa exploratória tem por finalidade aumentar a familiaridade do pesquisador com o tema pesquisado [8]. Considerando este aspecto, a pesquisa proposta nesse trabalho se caracteriza como um "estudo exploratóriodescritivo combinado", um tipo de estudo que tem como objetivo complementar análises encontradas em descrições quantitativas ou qualitativas por intermédio da obtenção da observação dos participantes da pesquisa [7]. No caso desta pesquisa, os participantes foram alunos de ensino fundamental que vivenciaram o uso da metodologia de ensino proposta por este trabalho, denominada GameMaking.

\subsection{Estudo de Caso como Estratégia de In- vestigação}

Para investigar a metodologia proposta e sua viabilidade, utilizou-se um estudo de caso. Durante este estudo de caso, alunos do nível fundamental tiveram que desenvolver em aulas de informática seus próprios jogos eletrônicos utilizando a ferramenta GameMaker.

Um estudo de caso é uma metodologia de investigação utilizada quando se busca compreender, analisar ou descrever acontecimentos nos quais estão envolvidos outros fatores referentes ao caso estudado [1].

Uma das vantagens vistas por pesquisadores que utilizam o método do estudo de caso é sua utilidade para desenvolver, contestar uma teoria, ou estabelecer uma base de situações em contextos reais para explicar uma situação referente a um fenômeno estudado [4]. Conside- rando estes aspectos, o estudo de caso deste trabalho utilizou um questionário online como forma de coleta de informações para analisar quantitativamente e qualitativamente a metodologia proposta. Tal questionário foi respondido pelos alunos de ensino fundamental que vivenciaram a metodologia de ensino proposta.

\section{Trabalhos Relacionados}

Para identificar trabalhos relacionados ao ensino de desenvolvimento de jogos com alunos do ensino fundamental, foi realizada uma revisão sistemática da literatura com o objetivo de identificar, analisar e interpretar as pesquisas relevantes para a área [11].

Para condução desta pesquisa, foram utilizadas as seguintes chaves de busca:

\section{- ("Computer Science" or "IT") and "Middle School" and "Games"}

Os engenhos de busca utilizados para a busca de trabalhos científicos relacionados foram ACM Digital Library(DL) ${ }^{1}$, IEEExplore ${ }^{2}$ e o Google Acadêmico. Utilizando as chaves de busca acima em português e inglês e também deixando menos específica a busca, foram encontrados durante a revisão bibliográfica alguns artigos relevantes relacionados a esta pesquisa e que são descritos a seguir. É importante destacar que no caso da ACM e IEEE a busca foi feita no abstract (resumo) dos artigos.

Considerando as buscas realizadas, alguns dos trabalhos relacionados encontrados se referem a estratégias para atrair alunos e principalmente garotas para a ciência da computação. Uma dessas estratégias é o uso de jogos como forma de introduzir o tema da tecnologia da informação. Segundo Battaiola, Domingues, Feijó et al. [2], o uso de jogos é útil para motivar as pessoas na aprendizagem de conceitos básicos da computação e na escolha da tecnologia da informação como profissão.

Outros trabalhos relacionados tratam do uso de atividades de desenvolvimento de jogos no ensino médio, a fim de promover uma melhoria na base de programação dos alunos que irão ingressar nos cursos de ciência da computação. Um destes trabalhos é o de Seabom, ElNasr, Milan et al. [19], onde se faz uso do GameMaker. Os autores apontam que suas experiências com alunos envolvidos no desenvolvimento de jogos geraram um impacto positivo nestes alunos com relação à compreensão de conceitos da computação e no desenvolvimento de jogos.

Um outro trabalho relacionado é o de Hardnett [6], onde o foco são alunos do ensino fundamental, com os quis se trabalha a construção de mundos virtuais interati-

\footnotetext{
${ }^{1}$ ACM DI : http://dl.acm.org/

${ }^{2}$ IEEE: http://ieeexplore.ieee.org/
} 
vos 3-D por meio da ferramenta Alice como forma de introduzir programação. Esses mundos virtuais podem ser jogos ou estórias animadas. O foco deste trabalho é no ensino fundamental pelo fato de pesquisas mostrarem que é nesta faixa etária onde os estudantes formam opiniões importantes sobre ciência e matemática ou sobre outras áreas nas quais têm interesse.

Além de trabalhos envolvendo jogos diretamente, outras abordagens têm sido utilizadas nas escolas para aproximar os alunos da computação. Uma delas é discutida por Scaico, Corlett, Paiva et al. [16], em um trabalho onde se apresenta uma metodologia baseada nas atividades de Tim Bell descritas livro "Computer Science Unplugged" (CSU), ou Computação Desplugada. A metodologia é direcionada ao nível médio de ensino e foi aplicada em escolas da rede pública de ensino a fim de desenvolver a capacidade de pensamento computacional nos alunos. Porém, apesar dos autores utilizarem conceitos de computação criativa, não foi observada neste trabalho a utilização da criação de jogos como meio de estimular essas pessoas para a computação.

\section{Ferramenta de Autoria Utilizada: GameMaker}

O GameMaker (GM) foi desenvolvido pela YoyoGa$\operatorname{mes}^{1}[21]$. A sua primeira versão foi projetada com o intuito de apoiar a elaboração de animações em 2D. Porém, muitos de seus usuários o utilizavam para criação de jogos para computadores. Para Overmars [14], o GM é considerado uma excelente ferramenta de autoria para criação de jogos computacionais. Embora a ferramenta ofereça a possibilidade de criar jogos através da linguagem de programação GML (GameMaker Language), nela se pode criar diversas modalidades de jogos sem a necessidade de inserir uma linha de código sequer.

Para desenvolvedores iniciantes em jogos, é necessário entender alguns elementos básicos existentes no GameMaker antes de iniciar a criação de um jogo. São eles: Sprites, Objects, Background e Rooms.

\section{- Sprites}

Sprites são definidos como imagens que ocupam uma parte da área gráfica de um jogo [2]. Um sprite pode ser uma única imagem ou uma representação do movimento de uma imagem (sprite composto).

\section{- Objects}

Para dar movimento aos personagens (criar sprites) de um jogo, é necessário criar um objeto (Object) que receberá esses "movimentos artificiais". Ou seja, cada objeto tem associado a ele um sprite para representá-lo.

${ }^{1}$ YoyoGames:http://wiki.yoyogames.com/index.php/Game_Maker
Neste aspecto, os Objects são os recursos mais importantes para criação de um jogo.

\section{- $\square \square \square \square$ ground}

Background são as representações de plano de fundo ou superfícies de um jogo em $2 \mathrm{D}$ e que proporcionam a ilusão de profundidade, de acordo com Ribeiro, Lucchese e Casnñeda [18].

\section{- $\square$ Room}

O elemento Room representa o cenário do jogo, que é composto por Sprites, Objects e Background. Nele se define também o nível do jogo [21].

\section{A Metodologia GameMaking}

Para elaboração desta metodologia envolvendo atividades de desenvolvimento de jogos eletrônicos utilizando a ferramenta GameMaker para alunos do ensino fundamental, foi necessário identificar na literatura que abordagem de ensino explorar. Foi necessário também planejar formas atrativas de introduzir a computação por meio de jogos digitais para alunos do ensino fundamental.

Uma teoria encontrada na literatura relevante para inserir em sala de aula é conhecida como "educação programada" ou "behaviorismo de Skinner" ou "teoria comportamentalista". Segundo tal teoria, a aprendizagem pode ser considerada como uma alteração do comportamento que é ensinado através de reforços imediatos e contínuos a uma resposta [15].

Para Souza [17], a teoria comportamentalista surge da necessidade de uma metodologia planejada, onde o professor transmite o conteúdo em pequenas partes direcionando o aprendizado. Os alunos seguem as prescrições dos professores na medida em que vão cumprindo com suas atividades.

Estabelecer um ambiente educacional para levar aos alunos do ensino fundamental uma metodologia que permitisse motivá-los para a computação foi um dos objetivos deste trabalho. Sendo assim, foi necessário um planejamento pedagógico sobre a forma de melhor introduzir o tema de desenvolvimento de jogos com o GameMaker para estes alunos e também se precisou desenvolver um material básico de apoio às aulas que iriam acontecer. Propõe-se, segundo a metodologia de ensino $G a-$ meMaking, que as aulas sejam organizadas em quatro etapas:

(1) Apresentação da ferrramenta e criação de grupos para execução das atividades;

(2) Criação dos personagens e cenário do jogo;

(3) Animação dos personagens; e 


\section{(4) Conclusão do jogo.}

A cada aula deve ser realizada uma demonstração do processo de criação do jogo a ser desenvolvido. Essa apresentação tem como intuito motivar o desenvolvimento de atividades semelhantes por parte dos alunos baseadas na explicação do professor.

\subsection{Apresentação da Ferramenta e Criação de Grupos para Execução das Atividades}

A primeira etapa da metodologia de ensino proposta refere-se à divisão das turmas em equipes para criação do jogo. As turmas podem ser divididas em grupos de 2 a 5 pessoas de acordo com a quantidade de computadores disponíveis no laboratório da escola. Outra atividade realizada em sala de aula nesta primeira etapa é a apresentação da ferramenta GameMaker (GM) aos grupos anteriormente formados. Durante esta atividade, devem ser demostradas as principais funções do GM e deve-se proporcionar um primeiro contato dos alunos com a ferramenta.

\subsection{Criação dos Personagens e Cenário do Jogo}

Nesta etapa é proposto aos alunos como exercício o desenvolvimento de um jogo simples, mas que lhes atraia. Um possível jogo a utilizar é um jogo baseado em labirintos, onde o personagem principal tem que vencer alguns obstáculos para conquistar sua liberdade. Para auxiliar os alunos nesta atividade, devem ser mostrados exemplos e deve-se entregar a cada grupo um tutorial simples sobre o GameMaker. A Figura 1 ilustra a produção da primeira parte do jogo proposto por alunos com a ajuda de um pequeno tutorial sobre o GameMaker desenvolvido para dar suporte aos discentes. Um exemplo de tutorial a utilizar está disponível no seguinte endereço eletrônico: http://goo.gl/COHc7B. Esse tutorial foi planejado de maneira que os alunos pudessem acompanhar passo a passo as atividades sugeridas pelo professor. Estas atividades consistiram no desenvolvimento dos elementos do jogo: Sprites, Objects, Background e Room.

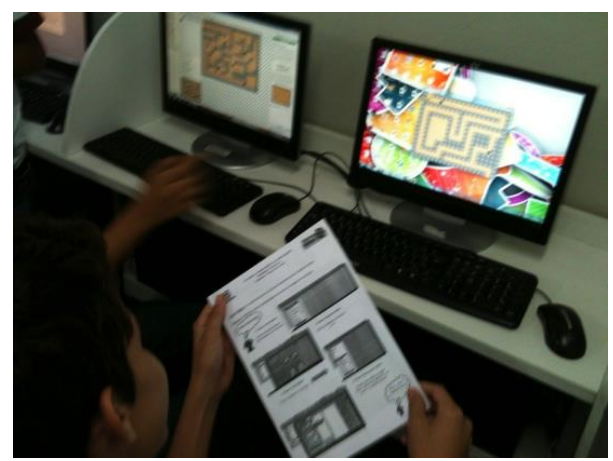

Figura 1 - Alunos criando o jogo proposto com ajuda de tutorial

\subsection{Animação dos Personagens}

A próxima etapa proposta pela metodologia corresponde a uma ou mais aulas em que o foco dos alunos deve ser na animação dos personagens que compõem o jogo proposto. Esta etapa é a mais importante para o desenvolvimento de um jogo, pois necessita de conhecimentos importantes sobre a ferramenta GameMaker, e em particular sobre a manipulação de objetos. Esta etapa é decisiva para o sucesso da finalização do jogo e durante sua execução o professor deve estar bem próximo aos alunos, acompanhando a execução de suas atividades. Embora existam diversas funções do GM para atribuir animação aos personagens, se houver um foco em apenas algumas, é possível que os alunos acompanhem bem essa fase.

\subsection{Conclusão do Jogo}

A última etapa da metodologia consiste em uma ou mais aulas para auxiliar os alunos na conclusão do seu jogo. A ideia é que nessas aulas o professor possa acompanhar de perto cada grupo e que promova discussões entre seus membros para que possam concluir com sucesso a atividade proposta. As imagens da Figura 2 mostram cenários que podem ser desenvolvidos ao fim dessa etapa. Estas imagens, em particular, foram extraídas de um jogo desenvolvido por alunos do sexto ano do ensino fundamental.
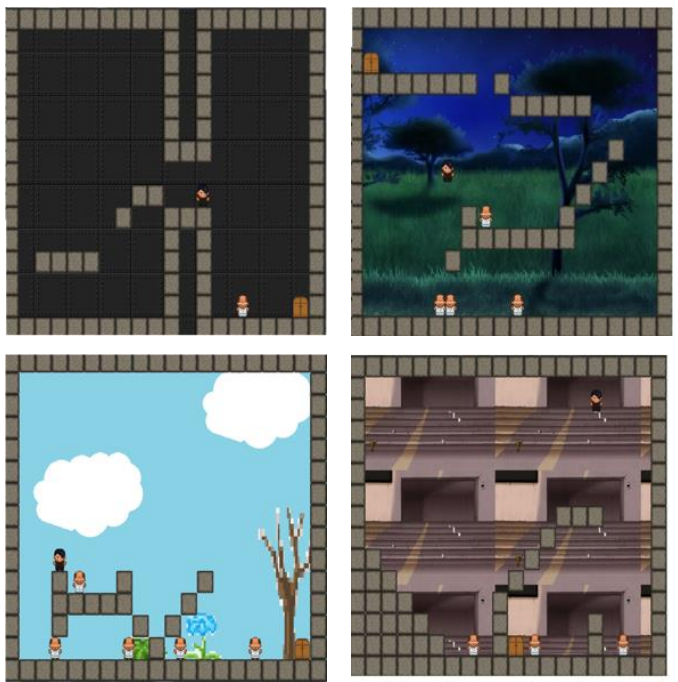

Figura 2 - Cenários do jogo desenvolvido por alunos do sexto ano.

\section{Estudo de Caso Realizado}

Após a realização da revisão bibliográfica e elaboração da metodologia "GameMaking”, descrita na seção anterior, verificou-se a necessidade de um estudo de caso com alunos do ensino fundamental para avaliar o uso desta metodologia na prática. 


\subsection{Público-alvo e Local da Pesquisa}

As turmas escolhidas para a realização do estudo de caso foram 10 turmas do $6^{\circ}$ ao $9^{\circ}$ ano do ensino fundamental de uma escola particular, situada na cidade de João Pessoa. As aulas em que se estimulou a criação de jogos seguindo a metodologia proposta neste trabalho e apresentada a seguir foram ministradas no período de 29 de Outubro a 30 de Novembro de 2012. Cada etapa da metodologia foi executada em uma aula. A escola onde foi realizado o estudo possui um laboratório de informática contendo 20 computadores de plataforma Windows, Datashow e Lousa Digital.

\subsection{Acompanhamento do Estudo de Caso}

$\mathrm{O}$ estudo de caso foi realizado por meio de quatro aulas seguindo a metodologia proposta, tendo cada aula um tempo de duração de 50 minutos.

As primeiras aulas em cada turma foram tranquilas e consistiram na divisão das equipes e apresentação da ferramenta. Apesar de alguns alunos tentarem optar por realizar as atividades individualmente, foi fácil contornar essa situação mostrando a importância do trabalho em grupo. Quanto à apresentação da ferramenta, alunos do $6^{\circ}$ ao $7^{\circ}$ ano queriam adiantar o cronograma das atividades e na primeira aula começarem a desenvolver seus jogos. Quanto aos discentes do $8^{\circ}$ e $9^{\circ}$ anos, viu-se que achavam interessante, mas houve casos em que próximo ao fim desta primeira aula alguns alunos pediam para que o professor liberasse $\mathrm{o}$ acesso às redes sociais.

O segundo encontro foi caraterizado pela entrega do tutorial de apoio para cada grupo e construção dos primeiros aspectos do jogo de labirintos. Percebeu-se que, de posse do tutorial, os alunos do $8^{\circ}$ ao $9^{\circ}$ ano conseguiram desenvolver as atividades sem a necessidade da explicação ou ajuda do professor. Considerando as turmas do $6^{\circ}$ ao $7^{\circ}$ ano, viu-se que alguns grupos sentiram a necessidade de pedir ajuda ao professor. Um dos fatores que podem ter levado a essa necessidade foi o número elevado de alunos por turma (uma média de 35 alunos).

A terceira aula foi caracterizada pela animação dos jogos. Nessa etapa foi identificado que ao finalizar as animações e aplicar testes para identificar se realmente os personagens do jogo estavam de acordo com o proposto, alguns computadores não permitiam que esse teste fosse feito. Isso ocasionou uma frustação por parte de alguns alunos. Outro ponto identificado foi a necessidade de auxiliar todos os grupos na manipulação de objetos, pois o GameMaker fornece muitos componentes e isso causou uma certa dificuldade aos alunos. Porém, apesar dessa necessidade, cerca de $90 \%$ dos alunos participaram das aulas de desenvolvimento de jogos, ou seja, um pú- blico total de 301 alunos.

$\mathrm{Na}$ quarta aula os alunos tiveram de concluir o jogo proposto. Além disso, ao fim dessa aula, eles foram convidados a responder a um formulário online de avaliação da metodologia empregada nas suas aulas de informática.

143 alunos responderam anonimamente no laboratório de informática o questionário avaliativo contendo 10 questões objetivas e discursivas. Adiante serão detalhados os resultados obtidos nesta pesquisa.

\subsection{Resultados}

\subsubsection{Caracterização da Amostra}

Os participantes que responderam o questionário do estudo de caso foram no total 142 alunos. A Figura 3 resume a distribuição por série dos participantes que responderam o questionário. De acordo com o gráfico, a maioria dos alunos são do $7^{\circ}$ ano, totalizando $40,56 \%$ da amostra. $25,17 \%$ são alunos do $6^{\circ}$ e outros $25,17 \%$ são do $8^{\circ}$ ano. Apenas $9,09 \%$ dos que responderam estavam cursando o $9^{\circ}$ ano. Esse valor inferior observado para os alunos que estão cursando o $9^{\circ}$ ano se deve ao fato da escola apresentar apenas duas turmas de alunos nesta série.

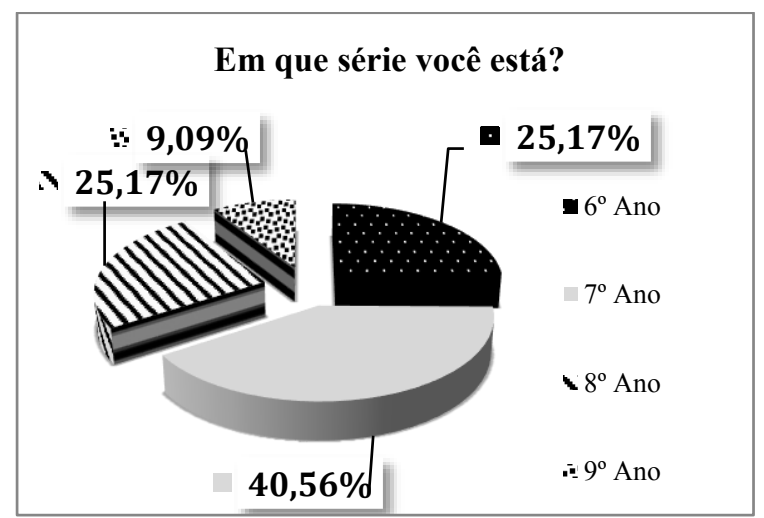

Figura 3 - Distribuição dos participantes

\subsubsection{Viabilidade do Desenvolvimento da Me- todologia Proposta}

Para analisar se houve sucesso por parte dos alunos com o desenvolvimento do jogo eletrônico proposto em sala de aula, lhes foi perguntado se eles conseguiram concluir os jogos. De maneira geral, viu-se que $54,55 \%$ dos alunos conseguiram concluir. Observou-se que $63,89 \%$ dos alunos do $6^{\circ}$ ano e $55,17 \%$ da turma do $7^{\circ}$ ano responderam o questionário afirmando que conseguiram concluir o desenvolvimento de seus jogos, conforme ilustrado pela Figura 4. Além disso, observou-se que $41,7 \%$ dos alunos do $8^{\circ}$ ano e $61,54 \%$ dos alunos do $9^{\circ}$ ano conseguiram concluir seu jogo. Neste caso, um dos 
possíveis fatores observados em sala de aula que ocasionaram o insucesso da conclusão do jogo por parte dos alunos do $8^{\circ}$ ano e de outros anos refere-se à falta de interesse de alguns dos alunos. Observou-se que alguns preferiam utilizar o computador nas aulas de informática para navegar nas redes sociais ou acessar sites de entretenimento.

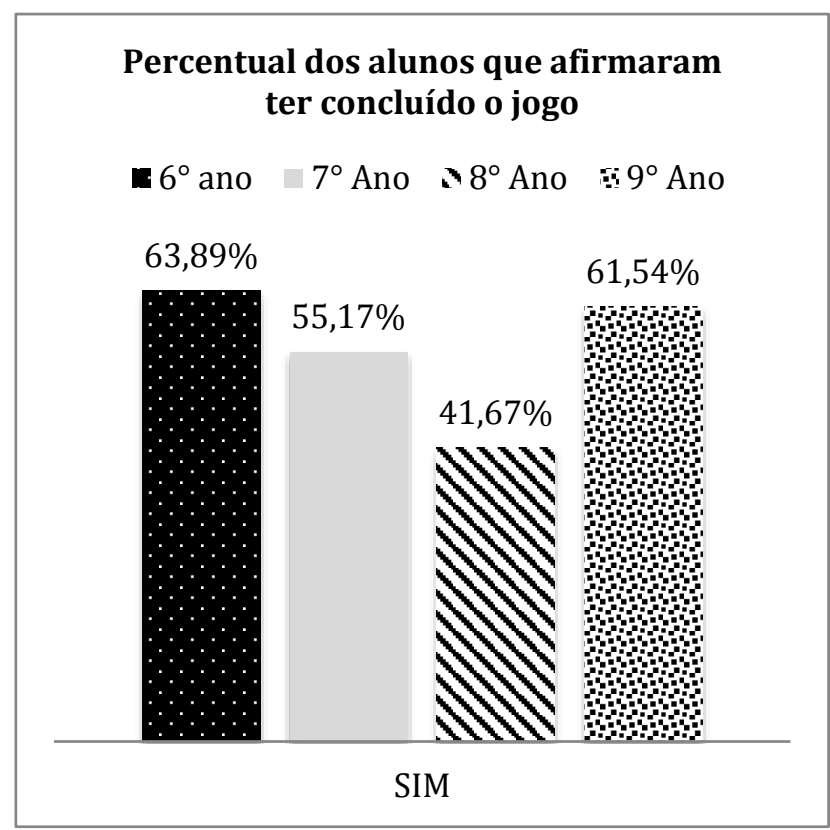

Figura 4 - Percentual de Alunos que conseguiram concluir o desenvolvimento do jogo proposto

Considerando os alunos que não foram capazes de finalizar a criação do seu jogo, foram investigadas as principais causas identificadas pelos alunos e que estão ilustradas na Figura 5. Viu-se que $26,15 \%$ dos que não concluíram atribuíram a causa disto a problemas ao utilizar o computador, como mensagens de erro ao executar o GameMaker. Outro problema observado foi a dificuldade de alguns alunos devido ao fato de terem perdido alguma das aulas sobre o tema. Conforme mostrado na Figura $24,62 \%$ dos alunos que não concluíram afirmaram ter perdido uma ou mais aulas sobre desenvolvimento de jogos. Um dado interessante é que apenas 6,15\% dos alunos apontaram como motivo da não conclusão do jogo o fato de não pretenderem concluí-lo. Desta forma, podese concluir que essa proposta foi bem aceita pelos estudantes. $20 \%$ dos que não concluíram atribuíram seu insucesso a não saberem fazer o que era pedido, algo que pode ser resultante das outras opções de causas. Segundo se pôde observar durante as aulas, alguns alunos não conseguiram terminar seu jogo devido à falta de entrosamento da equipe e este pode ter sido um dos motivos de insucesso de alguns. $23,08 \%$ dos alunos que não conseguiram concluir seu jogo apontaram como causa outros motivos (além das opções apresentadas no questionário), mas a maioria não explicitou tais motivos. Alguns dos que explicitaram possíveis causas apontaram aspectos como: "Meus colegas fizeram tudo por mim", "O computador travou muito", "Não consegui acompanhar as aulas do professor"

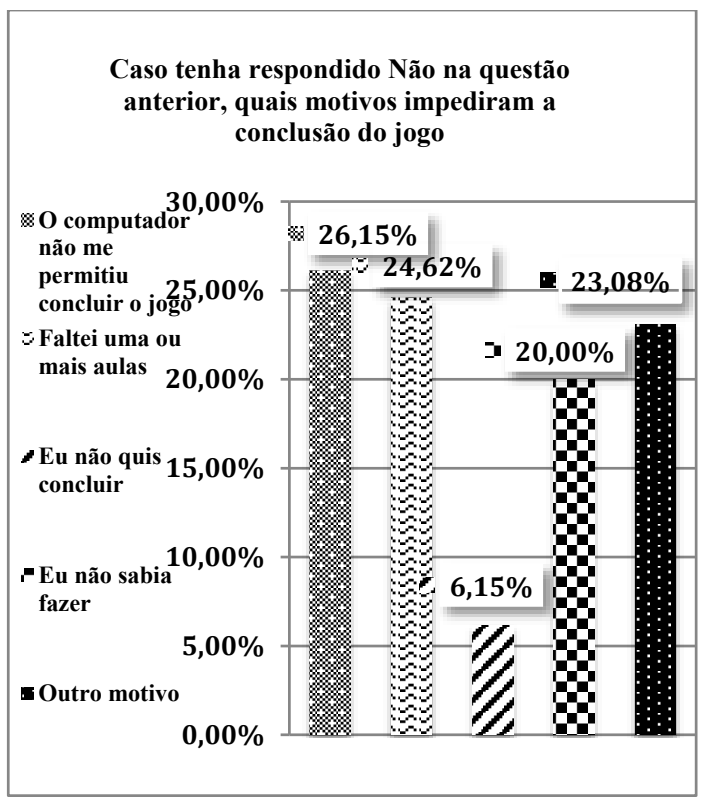

Figura 5 - Causas apontadas pelos alunos para não terem concluído com sucesso o desenvolvimento do jogo proposto

\subsubsection{Nível de Dificuldade no Desenvolvimen- to}

Outra análise feita a partir dos dados dos que responderam ao questionário referiu-se ao grau de dificuldade que eles tiverem para criar seus jogos. Para analisar o nível de dificuldade dos alunos diante da criação do jogo, os mesmos poderiam escolher entre as opções: (I) muito fácil, (II) fácil, (III) nem fácil nem difícil, (IV) muito difícil e (V) difícil. A Figura 6 mostra que a maioria dos alunos acharam que a atividade de criação dos jogos não era fácil e nem difícil ou então que era fácil. 34,27\% dos alunos acharam que era fácil e 9,79\% apontam essa tarefa como muito fácil. Uma parcela muito pequena dos alunos (3,5\%) considerou a elaboração de jogos difícil ou muito difícil. Desta forma, pode-se observar que a maioria dos alunos não encontrou grandes dificuldades em desenvolver seus jogos.

Analisando as respostas por série pôde-se constatar que para os alunos do $6^{\circ}$ e $7^{\circ}$ ano as opções mais representativas foram "fácil" e "nem fácil e nem difícil". Para as turmas do $8^{\circ}$ e $9^{\circ}$ percebeu-se que um aluno de cada ano escolheu a opção "muito difícil", que não foi 
escolhida pelos alunos das outras séries. A opção "Difícil" foi escolhida apenas por dois alunos do $8^{\circ}$ ano e um do $7^{\circ}$ ano.

Os dados ilustrados na Figura 6 dão indícios de que a metodologia pode ser mais adequada para alunos do $6^{\circ} \mathrm{e}$ $7^{\circ}$ ano, mas que para todas as séries os alunos não demonstraram sentir dificuldade diante da atividade de criação do jogo. Um ponto que pode ter contribuído para esse pequeno índice de dificuldade foi o apoio dado pelo professor a cada grupo durante a construção do jogo.

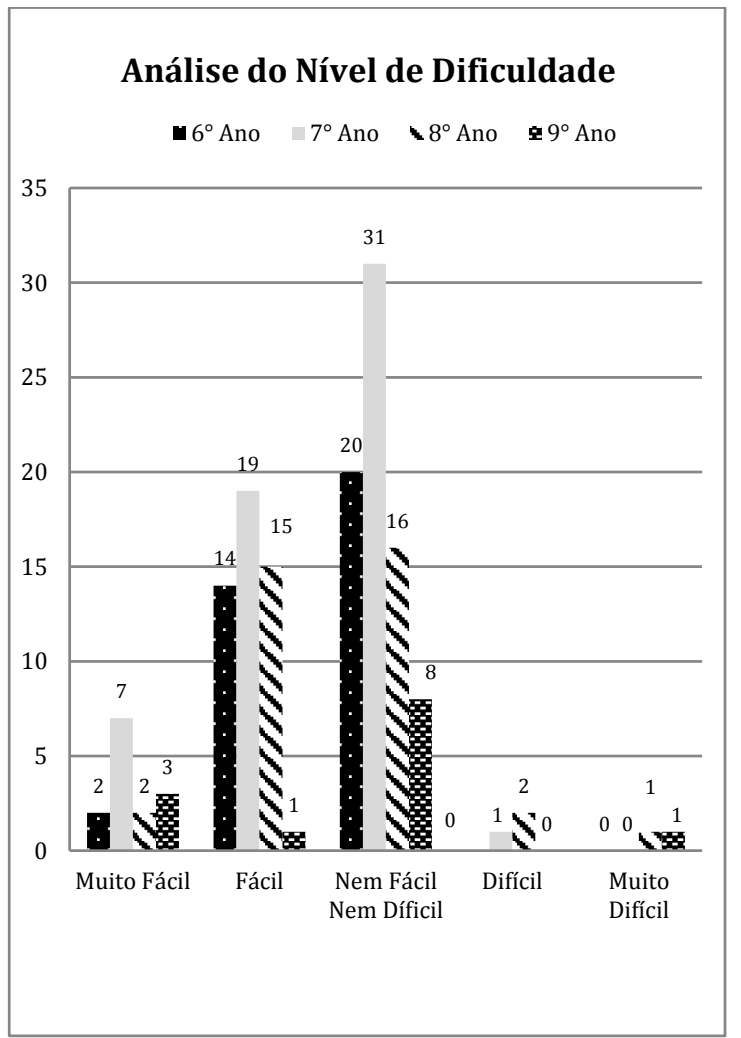

Figura 6 - Análise do nível de dificuldade percebido pelos alunos por série no desenvolvimento do jogo e dado pelo número de alunos que escolheu cada opção

Um outro fator que pode ter levado os alunos a não sentirem tanta dificuldade na elaboração do seu jogo, foi o tutorial distribuído em sala de aula pelo professor. Esse tutorial foi planejado para os alunos acompanharem passo a passo o desenvolvimento do jogo sugerido. A Figura 7 resume a opinião dos alunos sobre o tutorial criado pelo professor. Observou-se que $66 \%$ dos alunos afirmaram que este ajudou bastante no desenvolvimento do jogo, $22 \%$ responderam que ajudou pouco, $8 \%$ dos entrevistados afirmaram que não olharam para o tutorial e $3 \%$ afirmaram que o tutorial não lhes ajudou.

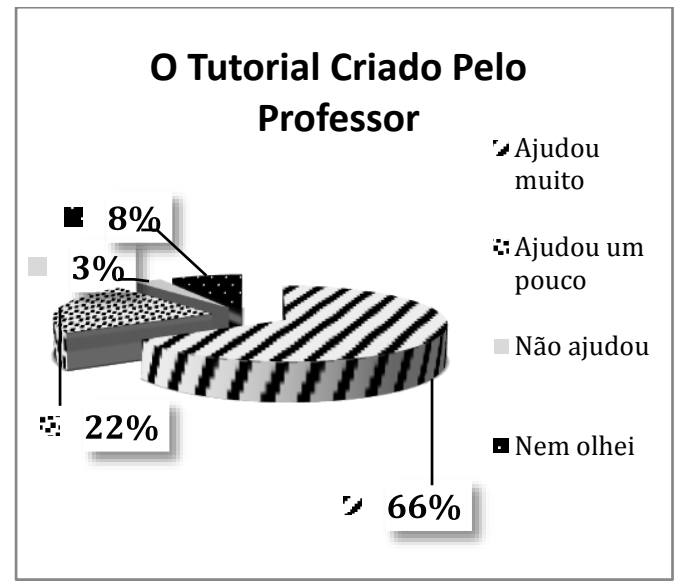

Figura 7 - Análise do tutorial criado pelo professor

\subsubsection{Satisfação dos alunos com as atividades}

Para analisar o nível de satisfação geral dos alunos com as aulas de informática destinadas ao desenvolvimento de jogos, pôde-se perceber ao observar a Figura 8 que de maneira geral os alunos aprovaram essa metodologia. Percebeu-se que a maioria dos alunos gostou (41\%) ou gostou bastante (47\%), o que evidencia um alto índice de aceitação da proposta.

Para os que optaram pelas opções "mais ou menos" (12 alunos no total, ou 8\%) e "não gostei" ( 3 alunos) ou "não gostei de jeito nenhum" (2 alunos), os mesmos indicaram através do questionário que não conseguiram obter o conhecimento específico para criação do jogo ou não gostavam de jogos computacionais.

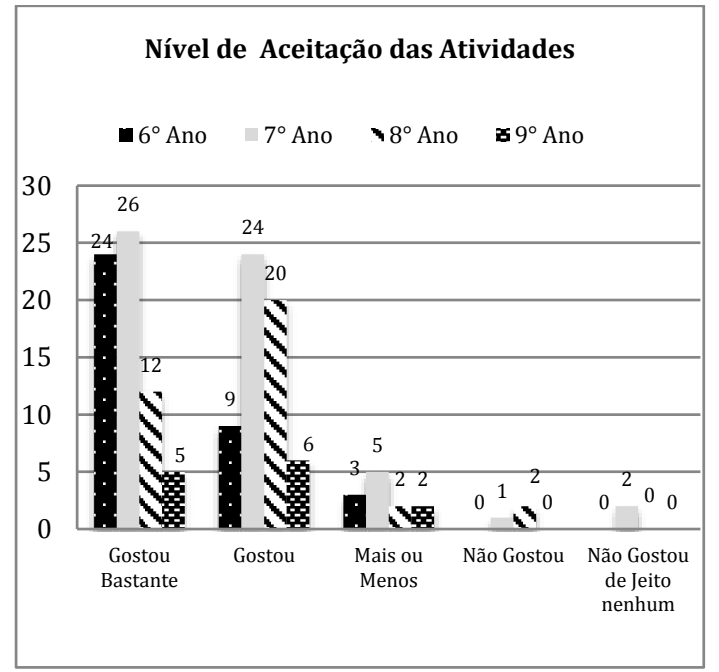

Figura 8 - Análise do nível de satisfação com as atividades em quantidade de alunos de cada série para cada resposta

Acredita-se que os dados obtidos mostram um bom nível de aceitação dos alunos com relação às atividades propostas. Observou-se também que alunos do 
ensino fundamental possuem habilidades para tais atividades desde que sejam guiados e estimulados por uma prática educacional.

Nessa mesma perspectiva de aceitação pelos alunos da metodologia proposta, eles foram questionados a respeito do jogo utilizado para os exercícios. Essa análise foi feita pois foi um grande desafio identificar um tipo de jogo que não fosse muito complexo, mas que mesmo assim atraísse os alunos das faixas etárias do ensino fundamental. Perguntou-se, portanto, se o jogo proposto foi interessante como atividade inicial na área de desenvolvimento de jogos. Observou-se que a maioria dos alunos considerou o jogo interessante. $72,22 \%$ dos alunos do $6^{\circ}$ ano e $67,24 \%$ dos alunos do $7^{\circ}$ ano gostaram do jogo. Esta aceitação também ocorreu entre os alunos do $8^{\circ}$ e $9^{\circ}$ Ano, onde $88,89 \%$ e $76,92 \%$, respectivamente, confirmaram que acharam o jogo interessante. Um dos fatores que podem ter levado alguns alunos a não acharem a proposta do jogo interessante, segundo alguns comentários feitos em sala, foi o fato de alguns desejarem fazer um jogo com mais recursos tecnológicos (três dimensões, áudio, multiplayer e etc.). Alguns alunos comentaram também que esperavam jogos esportivos, como futebol ou de automobilismo, mas que seriam mais complexos de serem feitos.

De maneira geral observou-se então que o jogo a ser trabalhado durante o desenvolvimento desta metodologia de ensino foi bem aceito pelos alunos.

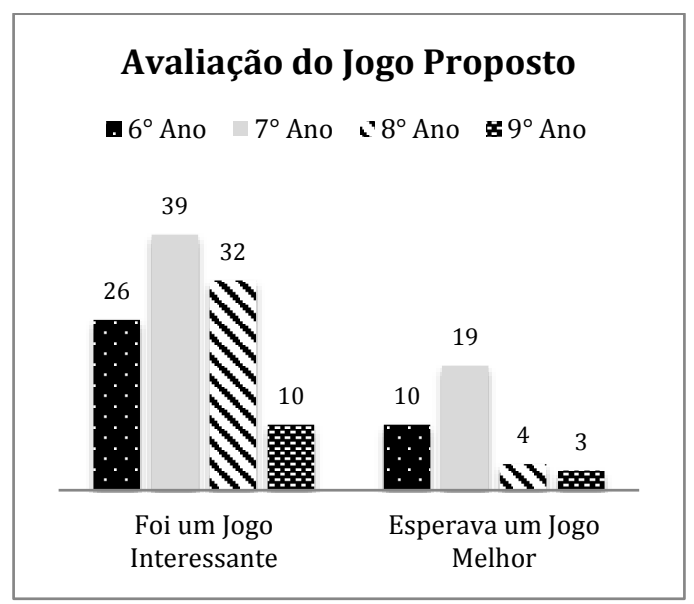

Figura 9 - Aceitação dos alunos quanto ao jogo proposto considerando a quantidade de alunos por série para cada resposta

Em relação à avaliação geral da metodologia adotada pelo professor em sala de aula, a Figura 15 resume o quadro de notas dadas pelos alunos às aulas de informática focando na criação de jogos. 49,65\% dos entrevistados deram nota 10 para o método de ensino adotado. 40 alunos, que correspondem a $27,97 \%$ dos participantes, atribuíram nota 9 . Apenas 7,69\% dos entrevistados escolhe- ram notas inferiores a 7 . A média aritmética geral das notas atribuídas pelos alunos foi de 8,8. As médias aritméticas das notas dadas pelos alunos do $6^{\circ}, 7^{\circ}, 8^{\circ}$ e $9^{\circ}$ anos foi respectivamente de 9,33, 8,64, 9,06 e 7,92, o que demonstra uma menor aceitação por parte dos alunos do $9^{\circ}$ ano quando comparada com a aceitação dos demais alunos.

Esta avaliação mostrou que a experiência foi bastante positiva para a maioria dos alunos. No entanto, foram também levantados os aspectos que poderiam ser melhorados em experiências futuras semelhantes. Algumas das sugestões dadas foram: "Usar aplicativos de criação de jogos mais avançados". Outro aluno sugere ainda: "Que cada aluno deveria ficar sozinho em um computador". Outro aluno fez a seguinte proposta: "traduzir o programa para o português."

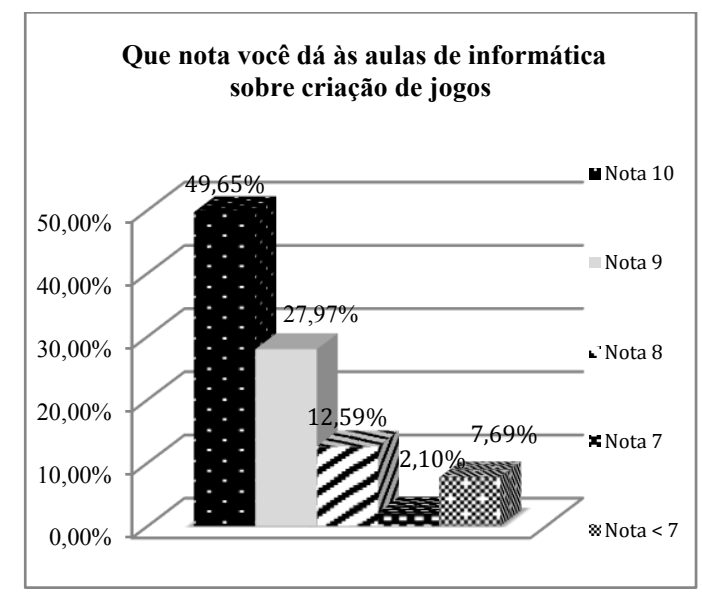

Figura 10 - Notas referentes as aulas de informática

\section{Considerações Finais e Trabalhos Futuros}

Conclui-se que, de maneira geral, este trabalho atingiu seus objetivos. Observou-se que era viável o desenvolvimento de jogos com alunos do ensino fundamental por meio da metodologia proposta. Através do estudo de caso realizado viu-se que a metodologia proposta foi bem aceita pelos alunos, uma vez que os resultados obtidos a partir do questionário aplicado foram bem positivos. Sendo assim, conclui-se que é possível utilizar o desenvolvimento de jogos como atividade para alunos do ensino fundamental e que a metodologia empregada por este trabalho mostrou ter uma boa aceitação por parte dos alunos do $6^{\circ}$ ao $9^{\circ}$ ano da escola onde foi realizado o estudo de caso.

Apesar do alto grau de satisfação dos alunos com esta proposta pedagógica, acredita-se que dois fatores melhorariam bastante essa metodologia: (1) Tempo, pois como 
houve pouco tempo para planejar e aplicar as aulas, é possível que com mais aulas para cada etapa se tivesse resultados melhores; (2) Máquinas insuficientes, pois algumas turmas possuíam uma grande quantidade de alunos e isso fazia com que a participação dos alunos não fosse tão efetiva quanto se houvesse um computador por aluno.

São planejados como trabalhos futuros deste trabalho melhorias pedagógicas considerando as sugestões dadas pelos alunos na avaliação inicial ou outras sugestões que sejam ofertadas em uma avaliação posterior contando com outros alunos e outros professores de outras escolas e observando algumas melhorias na metodologia comentadas a seguir.

Viu-se que é necessário propor ajustes a esta metodologia para alunos do $8^{\circ}$ e $9^{\circ}$ ano, podendo um destes ajustes ser a utilização de jogos com grau de dificuldade e recursos multimídias elevados (ex: jogos 3D, áudio, etc).

Os resultados levantados apontam que este público alvo não aceitou tão bem a proposta do jogo sugerida pelo professor como os alunos do $6^{\circ}$ ao $7^{\circ}$ ano. Além disso, percebeu-se em vários alunos a ansiedade em explorar mais recursos em seus jogos e que isso pode ser explorado melhor. Acredita-se que em novas avaliações da metodologia podem ser explorados recursos avançados do GM. Outro ajuste que pode ser inserido na metodologia é utilizar mais de um tutorial ou estender o tutorial atual para que com turmas grandes o professor não tenha dificuldades para atender a todos os grupos, como foi observado na aula sobre animação dos personagens.

Espera-se também que com base nesta metodologia se possa propor uma outra explorando também o uso de linguagens de programação no desenvolvimento dos jogos eletrônicos propostos.

\section{Referências}

[1] C. Araújo, E. M. F. Pinto, J. Lopes, O estudo de caso: Métodos de Investigação em Educação. Revista Portuguesa de Educação - Universidade do Minho, 21(1): 101-107, 2008.

[2] A. L. Battaiola, R. G. Domingues, B. Feijó et al. Desenvolvimento de Jogos em Computadores e Celulares. RITA: Revista de Informática Teorica e Aplicada, 8(2): 7-46, 2001.

[3] G. Carmichael. Girls, Computer Science, and games. SIGCSE Bulletin, 40(4): 107-110, 2008

[4] L. M. Dooley. Case Study Research and Theory Building. Advances in Developing Human Resources(4), 335-354, 2002.
[5] T. R. Grover. Using games to introduce middle school girls to computer science. J. Comput. Small Coll. 24, 132-138, 2009.

[6] C. R. Hardnett., Gaming for Middle School Students: Building Virtual Worlds. In Proceedings of the International Conference on Game development in Computer Science Education, páginas 21-25, 2008.

[7] E. M. Lakatos, M. A. Marconi. Metodologia do Trabalho Cientifico: procedimento básicos, pesquisas bibliográficas, projeto e relatórios, publicações e trabalhos cientificos. 6a. Ed. 7a. Reimpr. Atlas, São Paulo, 2006.

[8] E. M. Lakatos, M. A. Marconi. Técnicas de Pesquisa: planejamento e execução da pesquisa, amostragens e técnicas de pesquisa, elaboração, análise e interpretação dos dados . 6a. Ed. Atlas, São Paulo, 2006.

[9] V. J. Leffa. Uma ferramenta de autoria para o professor: o que é e o que faz. Letras de Hoje, 41(144), 189-214, 2006.

[10] C. Lucena, H. Fuks. A Educação na Era da Internet. Clube do Futuro, 1(1), 55-66, 2000.

[11] B. A. Kitchenham. Procedures for undertaking systematic reviews. Technical report, Computer Science Department, Keele University, 2004.

[12] J. C. Koche. Fundamentos de metodologia científica: teoria da ciência e prática da pesquisa. 15 . ed. Vozes, Petrópolis-RJ, 1997.

[13] J. Mattar. Games em educação: como os nativos digitais aprendem. Pearson Prentice Hall, São Paulo, 2010.

[14] M. Overmars. Designing Games With GameMaker.

http://sandbox.yoyogames.com/downloads/docs/ gmaker80.pdf. Set. 2013.

[15] A. R. Prass. Teorias da aprendizagem. http://www.fisica.net/monografias/Teorias de A prendizagem.pdf. Set. 2008.

[16] P. D. Scaico, E. F. Corlett, L. A. Paiva et al, Relato da Utilização de uma Metodologia de Trabalho para o Ensino de Ciência da Computação no Ensino Médio. In Anais do Congresso Brasileiro de Informática na Educação - 180 Workshop de Informática na Escola, Rio de Janeiro, 2012.

[17] V. L. Souza. Agentes Pedagógicos em Ambientes Hipermídia: Um Novo Design para Aprendizagem. Dissertação, Universidade Federal de 
Santa Catarina, Florianópolis, 2002.

[18] B. Ribeiro, F. Lucchese, Z. Casnñeda. Interfaces de Jogos Digitais. http://www.dca.fee.unicamp.br/ martino/discipli nas/ia369/trabalhos/t3g3.pdf. Out. 2013.

[19] K. Seabom, M. S. El-Nasr, D. Milan et al. Programming, PWNed: Using Digital Game Development to Enhance Learners' Competency and Self-Efficacy in a High School Computing Science Course. In Proceedings of the Technical Symposium on Computer Science Education. SIGCSE - Special Interest Group on Computer Science Education, páginas 93-98, 2012.

[20] L. M. R. Tarouco et. al. O aluno como coconstrutor e desenvolvedor de jogos educacionais. RENOTE: Novas Tecnologias na Educação. $\quad 3(2): \quad 1-8, \quad 2005$. http://www.seer.ufrgs.br/index.php/renote/article /view/14024/7914

[21] YoYo Games. http://wiki.yoyogames.com/index.php/Rooms. Set. 2013.

[22] L. L. Werner, S. Campe, J. Denner. Middle school girls + games programming $=$ information technology fluency. In Proceedings of the $6^{\text {th }}$ Conference on Information Technology Education, New York, NY, 301-305, 2005. 